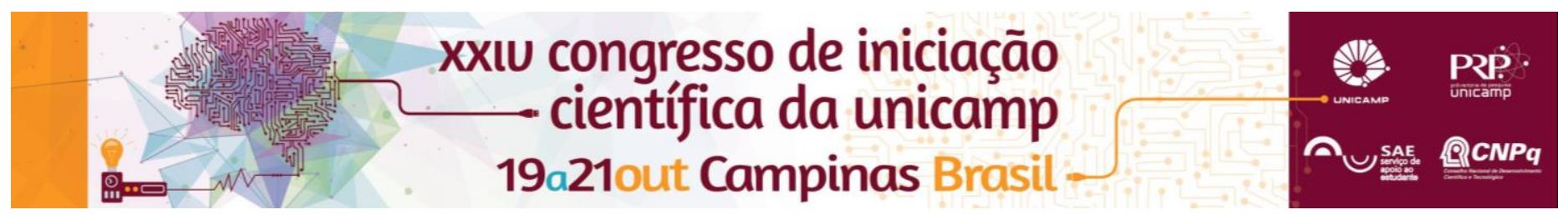

\title{
Criação de conteúdos para Oficinas de Robótica de baixo custo com utilização da Plataforma Arduíno.
}

\section{Lucas Rodriguez Braghetti.}

\section{Resumo}

O projeto tem por finalidade o desenvolvimento de conteúdos interdisciplinares para uma oficina de robótica de baixo custo. Estes serão fundamentais para que professores possam exemplificar o conteúdo teórico já existente, facilitando a compreensão de conceitos de física, matemática e eletrônica. Conceitos que são dificilmente compreendidos sem um exemplo prático. Tópicos como: Motores, ângulos, eletrônica, pilhas, entre outros.

\section{Palavras-chave \\ Arduino, Tecnologia, Educação}

\section{Introdução}

O projeto propõe a elaboração de protótipos em plataforma Arduíno UNO e alguns com o Intel Galileo, desenvolvidos no ambiente de programação Arduíno IDE, com objetivo de criar conteúdos educacionais para professores e alunos, exemplificando e facilitando o entendimento de conceitos de difícil compreensão envolvidos com física, matemática e eletrônica no formato de apostilas a partir do desenvolvimento de protótipos.

\section{Resultados e Discussão}

Neste projeto a metodologia adotada para a criação das apostilas foi voltada para pratica, mas sem deixar de canto a teoria, pois ela é de estrema importância para o bom andamento do projeto e principalmente para a qualidade do ensino de qualquer disciplina. Desta forma procuramos seguir um padrão durante a criação das apostilas, onde primeiramente introduzimos o conteúdo e explicamos grande parte da teoria, sempre tentado apresentar exemplos para a maior compreensão, e após ser apresentada uma base do conteúdo abordado, seguimos para a prática com a apresentação de projetos com o arduino e a programação, relacionados ao conteúdo, dividindo estes em níveis de dificuldade, que a cada projeto vai aumentando.

Outro ponto importante é o fato das ferramentas utilizadas para a criação de cada projeto envolvendo o Arduino serem de baixo custo, para que qualquer um possa a vir a utilizar as apostilas e seus conteúdos didáticos como uma ferramentas de aprendizado, em salas de aulas ou não.

\section{Conclusões}

Com este projeto pode se concluir que apesar da metodologia ser contestada, pois pessoas podem considera-la cara por utilizar a prática como ferramenta de ensino, o projeto como um todo mostra que é possível sim, e também se mostra como uma ferramenta diferenciada para atrair a atenção de estudantes, e mostrar novas maneiras de se aprender conteúdos que muitas vezes são considerados chatos, ou inúteis para eles, além de dar uma boa base a conteúdos relacionados à programação que tentam mostrar novas formas de se raciocinar e resolver problemas..

TELLES, DIRCEU DALKMIN / MONGELLI NETTO, JOÃO (ORGS.). Física com Aplicação Lógica:Mecânica Vol1. EDGAR BLUCHER, 2011.

Simon Monk. 30 Projetos com Arduino. Bookman. 2014.

Arduino.cc.Tutorial Blink. Disponível em < http://arduino.cc/en/Tutorial/Blink >. Acesso em: 10 de Abril 2015.

Simon Monk. Programação começando com Sketches. Bookman. 2014

MCROBERTS, Michael. Arduino Básico Editora. NOVATEC, $2^{\text {a }}$ edição, 2015 